\title{
Pemanfaatan Lahan Sempit Sebagai Tempat Budidaya Ikan Lele Organik Di Kampung Palangpang Kecamatan Ciemas
}

\author{
Suryaman ${ }^{1)}$, Rochadi Santoso ${ }^{2)}$, Dede Ropik Yunus ${ }^{3)}$ \\ 1),2) Prodi Keuangan Perbankan, STIE Ekuitas Bandung \\ 3) Prodi Manajemen, STIE Ekuitas Bandung
}

\begin{abstract}
Increasing people's welfare is not the responsibility of the government alone, but it requires active participation from the community, especially academics. This service was carried out with the aim of helping to find additional income alternatives for Palangpang villagers, where the majority of the population work as fishermen and farmers. Even though the village is near the coast and the economy of the people depends on sea products, there are people who are interested in studying freshwater fish farming such as catfish as an effort to find additional family income.

Utilization of the people's yard to cultivate catfish by using a tarpaulin pool, providing training and assistance on setting up pond water, selecting catfish seeds, choosing feed, water management, and marketing, although not yet significant, has helped the economy of some communities in Palangpang village. Harvesting is carried out after a 3 month maintenance period, and based on the calculation of the average daily income shows an increase from the original Rp. 30,000 to Rp. 35,000, -. It it can be concluded that catfish farming can be an alternative to improving people's welfare through the use of land.
\end{abstract}

Keywords: catfish cultivation, increased welfare

\section{Abstrak}

Peningkatan kesejahteraan masyarakat bukan tanggung jawab pemerintah semata, akan tetapi diperlukan partisipasi aktif dari masyarakat khususnya kalangan akademisi. Pengabdian ini dilaksanakan dengan tujuan untuk membantu mencari alternatif tambahan penghasilan warga kampung Palangpang, yang mayoritas penduduknya berprofesi sebagai nelayan dan petani. Meskipun kampung ini berada di dekat pantai dan perekonomian masyarakatnya tergantung dari hasil laut, akan tetapi sebagai masyarakat ada yang tertarik untuk mempelajari budi daya ikan air tawar seperti lele sebagai usaha mencari tambahan pendapatan keluarga.

Pemanfaatan pekarangan penduduk untuk membudidayakan lele dengan menggunakan kolam terpal bulat, pemberian pelatihan dan pendampingan tentang pengaturan air kolam, pemilihan benih lele, pemilihan pakan, pengelolaan air, dan pemasaran walaupun belum signifikan tetapi telah membantu perekonomian sebagian masyarakat di kampung Palangpang. Panen dilakukan setelah masa pemeliharaan 3 bulan, dan berdasarkan perhitungan rata-rata pendapatan sehari-hari menunjukkan peningkatan dari yang asalnya Rp.30.000,- menjadi Rp. 35.000,-. Kesimpulannya, bahwa budidaya ikan lele dapat menjadi salah satu alternatif peningkatan kesejahteraan warga melalui pemanfaatan lahan pekarangan.

Kata Kunci : budi daya lele, peningkatan kesejahteraan.

\section{PENDAHULUAN}

Pertumbuhan penduduk yang

diikuti dengan meningkatnya

kegiatan industri mengakibatkan

kehidupan nelayan di daerah
Ciemas menjadi semakin sulit.

Ketergantungan nelayan pada

cuaca, bahan bakar dan kurangnya

perlengkapan mengakibatkan

perolehan pendapatan nelayan 
setiap harinya tidak menentu. Pada musim tertentu nelayan tidak mempunyai pekerjaan, sehingga untuk keperluan sehari harinya seringkali nelayan meminjam uang dari rentenir. Untuk mengurangi kebiasaan nelayan meminjam pada rentenir maka diperlukan suatu usaha dari berbagai pihak untuk meningkatkan pendapatannya. Salah satunya adalah dengan memberikan modal, pelatihan, dan pendampingan keterampilan yang dapat meningkatkan kesejahteraan nelayan.

Program pengabdian yang dilaksanakan oleh tim pengabdi bertujuan untuk membantu nelayan mencari alternatif tambahan penghasilan selain dari menjual ikan hasil tangkapan ke tempat pelelangan akhir (TPA) melalui budidaya ikan lele. Pemilihan budidaya ikan lele berdasarkan alasan bahwa:

a. Walaupun tidak terlalu besar tetapi mayoritas rumah warga mempunyai pekarangan yang dapat dimanfaatkan selain bercocok tanam.

b. Ikan lele mempunyai pangsa pasar yang luas, harga yang murah, perawatan yang mudah, tidak memerlukan lahan luas, biaya produksi yang minimal.

c. Kampung Palangpang mempunyai akses transportasi yang bagus sehingga dapat memudahkan warga untuk beraktivitas jual beli.

\section{METODE PELAKSANAAN}

Berdasarkan identifikasi masalah yang telah diuraikan maka tim pengabdian memberikan solusi permasalahan melalui serangkaian kegiatan dengan melibatkan partisipasi aktif dari warga berupa:

a. Pemberian produk berupa kolam terpal bulat, pompa air, pipa, dan penunjang lainnya.

\section{b.Pelatihan:}

Pertama, warga diberi penjelasan tentang jenis jenis lele dan cara pemeliharaannya, setelah itu warga bersama tim pengabdian memutuskan untuk membeli benih ikan lele jenis sangkuriang dengan alasan telurnya lebih banyak dan pakannya lebih hemat. Pelatihan menggunakan leaflet yang tim pengabdi peroleh dari

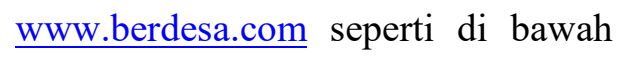
ini, 


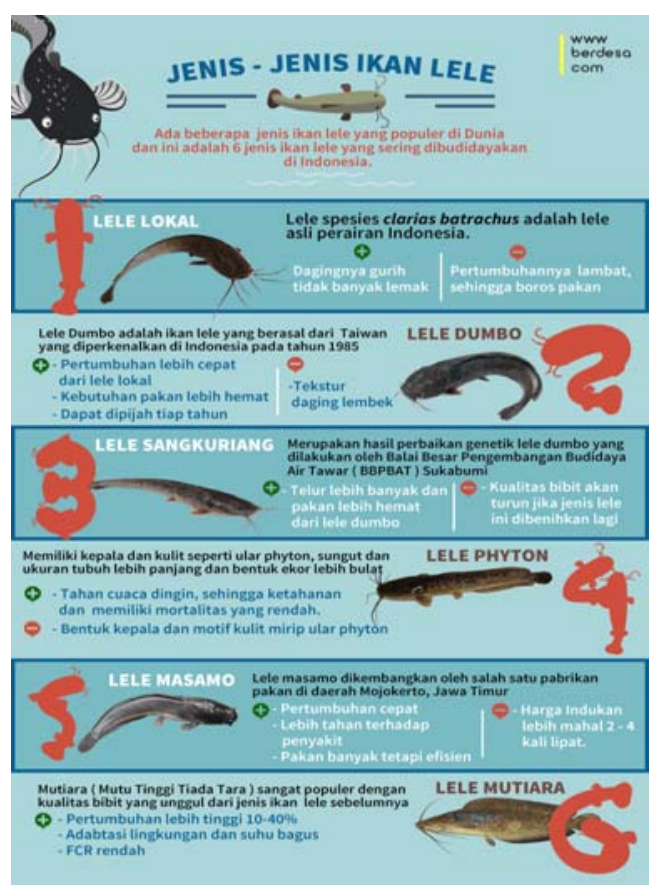

Gambar 1. Leaflet pelatihan

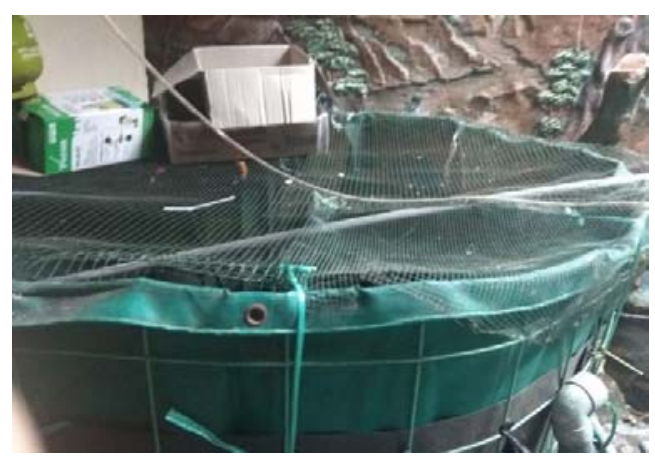

Gambar 2. Kolam terpal mitra

Kedua, pemberian pakan (pakan utama dan pakan tambahan). Pakan merupakan komponen yang paling banyak menghabiskan biaya. Oleh karena itu selain diberikan pakan utama perlu juga diberi pakan tambahan agar biaya produksi tidak terlalu mahal. Pemberian sisa makanan yang tersedia di sekitar lingkungan warga merupakan alternatif yang murah dan memungkinkan, meskipun akan sedikit mengganggu pertumbuhan dari lele yang sedang dikembangbiakan.

Ketiga, pemeliharaan kualitas air. Pemeliharaan air merupakan salah satu faktor penting dalam pemeliharaan ikan lele. Untuk mendapatkan kualitas air yang maksimal maka air tidak boleh banyak mengandung sisa pakan yang tidak habis di dasar kolam, karena akan menimbulkan gas amonia yang menyebabkan bau busuk. Untuk mengatasinya maka warga diharuskan membuang satu per tiga dari air kolam dan mengisinya kembali dengan air baru.

Adapun prosedur pelaksanaan pengabdian di Kampung Palangpang Kecamatan Ciemas adalah sebagai berikut:

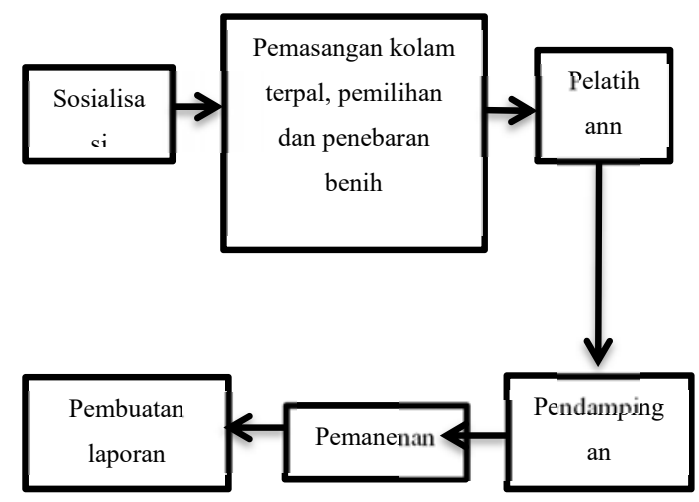




\section{HASIL DAN PEMBAHASAN}

Hasil yang dicapai dari pengabdian ini adalah peningkatan pendapatan dari warga yang membudidayakan ikan lele. Sebagai ilustrasi pengeluaran dan pemasukan yang didapat oleh warga adalah sebagai berikut:

Pengeluaran :

a. Pembelian benih ikan lele 5000 ekor (a) Rp.100,$=$ 500.000

b. Pembelian pakan 3 bulan (Feb sd

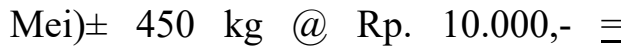
$\underline{4.000 .000}$.

Total modal yang dikeluarkan selama proses penanaman benih, pemeliharaan hingga pemanenan adalah

Rp.5.000.000,-

Pendapatan :

Bulan Mei 2019 telah dipanen seluruhnya dan diperoleh $\pm 450 \mathrm{~kg}$ dengan harga jual di pasaran $\mathrm{Rp}$. 17.500,-. Hasil penjualan Rp. 7.875.000,-, berarti keuntungan yang diterima oleh warga selama 3 bulan adalah Rp. 2.875.000,- atau warga mendapat tambahan pendapatan sekitar Rp. 950.000,- per bulannya.

Dari hasil pengabdian ini luaran yang diperoleh oleh warga adalah terjadinya peningkatan skill warga dalam membudidayakan ikan lele, peningkatan keterampilan ini secara langsung berdampak pada peningkatan pendapatan warga sehingga tingkat kesejahteraan warga dapat meningkat walaupun belum signifikan.

Luaran yang diperoleh oleh tim pengabdian adalah memperoleh kesempatan untuk mengaplikasikan pengetahuan dan kemampuan akademisnya untuk membantu warga sekitar, sesuai dengan peranan seorang dosen yaitu melaksanakan tridharma perguruan tinggi.

\section{PENUTUP}

Ada beberapa hal yang bisa disimpulkan setelah pengabdian ini selesai dilaksanakan yaitu:

a. Bertambahnya ketrampilan warga dalam membudidayakan ikan air tawar.

b. Warga dapat memanfaatkan lahan pekarangan untuk menambah penghasilan melalui budidaya ikan lele.

c. Walaupun belum signifikan akan tetapi telah terjadi peningkatan kesejateraan warga yang membudidayakan ikan lele 


\section{DAFTAR PUSTAKA}

Konstruksi Kolam Terpal, 2016. Analisis Biaya dan Keuntungan Ternak Lele di Kolam Terpal. https://www.konstruksikolamterp al.com/analisis-biaya-ternak-leledi-kolam-terpal/

Kurdianto, dkk. 2014. "Clarias MinaFlock" : Pemanfaatan Lahan
Sempit Sebagai Tempat Budidaya Ikan Lele Organik Superintensif Berbasis Bioflock Untuk Menunjang Pendapatan Warga Desa Purwasari, Bogor. Program Kreativitas Mahasiswa. Institut Pertanian Bogor. 